\title{
LEGAL ASPECTS OF 3D PRINTING
}

\author{
Victoria A. Ammalainen \\ Volgograd Academy of the Ministry of Internal Affairs of the Russian Federation, \\ Volgograd, Russian Federation
}

Introduction: the article discusses the legal aspect of 3D printing and computer 3D models, which are printed using a 3D printer. The prospects, threats and challenges that the development of 3D printing technologies entails are examined. The author comes to the conclusion that it is necessary to adapt the new technological realities to the current legislation and it is necessary to take into account which particular object will be displayed in the three-dimensional model, since this will determine which rights to objects will be affected. Methods: the methodological basis of this scientific article is a number of methods of scientific knowledge, among which the main place is occupied by methods of information processing and logical analysis, synthesis, induction, deduction and generalization. Results: the author's position on 3D models and their legal regulation is presented. Conclusions: as a result of the study, recommendations were made for improving the regulatory framework, the author proposes to delimit the legal protection of 3D models by amending Art. 1259, 1352 of the Civil Code of the Russian Federation.

Key words: 3D printing, three-dimensional printing, technology, protection of rights, legal aspects, responsibility, intellectual property law, protection, object, civil law.

Citation. Ammalainen V.A. Legal Aspects of 3D Printing. Legal Concept = Pravovaya paradigma, 2021, vol. 20, no. 3, pp. 138-142. (in Russian). DOI: https://doi.org/10.15688/lc.jvolsu.2021.3.20

УДК 347

ББК 67.404 .3
Дата поступления статьи: 09.04.2021

Дата принятия статьи: 05.06.2021

\section{ПРАВОВЫЕ АСПЕКТЫ ЗD-ПЕЧАТИ}

\author{
Виктория Алексеевна Аммалайнен \\ Волгоградская академия Министерства внутренних дел Российской Федерации, \\ г. Волгоград, Российская Федерация
}

Введение: в статье рассматривается правовой аспект трехмерной печати и компьютерных 3D-моделей, печать которых осуществляется с использованием 3D-принтера. Анализируются перспективы, угрозы и вызовы, которые несет в себе развитие технологий трехмерной печати. Автор приходит к выводу, что необходимо адаптировать новые технологические реалии к действующему законодательству, при этом следует учитывать отображаемый в трехмерной модели объект, так как от этого будет зависеть, какое право на объекты будет затрагиваться. Методы: методологической основной данной научной статьи является ряд методов научного познания, среди которых обработка информации и логический анализ, синтез, индукция, дедукция и обобщение. Результаты: изложена авторская позиция по поводу 3D-моделей и их правового регулироваحิ ния. Выводы: в результате проведенного исследования даны рекомендации по совершенствованию нормативной базы, автор предлагает разграничить правовую охрану 3D-моделей путем внесения изменений в ст. 1259,1352 ГК РФ.

Ключевые слова: 3D-печать, трехмерная печать, технология, защита прав, правовые аспекты, ответственность, интеллектуальное право, охрана, объект, гражданское право.

Цитирование. Аммалайнен В. А. Правовые аспекты 3D-печати // Legal Concept = Правовая парадигма. -2021.- T. 20, № 3. - C. 138-142. - DOI: https://doi.org/10.15688/lc.jvolsu.2021.3.20 


\section{Введение}

Использование 3D-печати в инновациях, творчестве, медицине, протезировании и в других сферах жизнедеятельности человека вносит большой вклад в окружающий мир. Она помогает в дизайне, производстве, позволяет создать свои собственные продукты, учитывая личные потребности каждого. Исследователи из Университета Мэриленда, Уханьского университета и Восточно-Китайского политехнического университета напечатали стволовыми клетками на 3D-принтере роговицу глаза [6]. 3D-печать не стоит на месте и постоянно развивается в различных направлениях и помогает внести значительный вклад во многие сферы жизнедеятельности.

Многие говорят о том, что с помощью 3D-печати можно будет создать что угодно: одежду, автомобильные запчасти, оружие, лекарства, продукты питания и т. д. По прогнозам исследователей, к 2025 г. до 10 \% всех потребительских товаров будет создаваться путем 3D-печати [8]. Вместе с этим возникают социальные, этические и правовые вопросы: если люди смогут распечатать, что захотят, как будут решаться проблемы, например, с нарушениями, связанными с интеллектуальной собственностью, и каким будет эффект от домашней полиграфии? Необходимо начать уже сейчас регулировать $3 \mathrm{D}-$-печать на законодательном уровне.

Что же такое 3D-печать? По сути, 3D-принтер - это машина, которая может превратить чертеж в физический объект. Принтер такого формата создает объекты слой за слоем [7], 3D-принтер может создавать объекты с внутренними подвижными частями. 3D-принтер может печатать отдельные детали и запасные части. Некоторые принтеры такого рода могут печатать свои собственные части тем самым самовоспроизводиться. Что бы начать 3D-печать, необходим чертеж, который создается с помощью компьютера с использованием программ проектирования CAD. Последние пользуются успехом у архитекторов, дизайнеров и инженеров, с их помощью становится возможным представить физические объекты, прежде чем они будут созданы в реальном мире. Один человек может создать новый объект, отправить дизайн по электрон- ной почте своему другу в другую страну, и он сможет распечатать идентичный объект.

3D-принтеры в настоящее время не относятся принтерам, которыми мы привыкли пользоваться в повседневной деятельности, но такие устройства, как 3D Systems Cube Silver 381000, Makerbot's Replicator 2X, 3D-принтер Wanhao Duplicator 10 White, делают эту возможность на шаг ближе к реальности, ведь 3D-принтер в настоящее время можно приобрести в магазине бытовой техники или заказать через Интернет. Уже сейчас 3D-принтеры пользуются большим спросом среди населения. Люди, ставшие обладателями такого рода принтеров, пытаются найти и распространить 3D-модели через Интернет, при этом не хотят тратить денежные средства на покупку $3 \mathrm{D}$-моделей, а хотят получить их бесплатно, из-за этого происходит незаконное распространение трехмерных моделей через Интернет.

\section{D-модель как объект гражданского права}

Ст. 128 Гражданского кодекса Российской Федерации (далее - ГК РФ) закрепляет исчерпывающий перечень объектов гражданского права. Так, к объектам гражданского права относятся вещи (включая наличные деньги и документарные ценные бумаги), иное имущество, в том числе имущественные права (включая безналичные денежные средства, бездокументарные ценные бумаги, цифровые права), результаты работ и оказание услуг, охраняемые результаты интеллектуальной деятельности и приравненные к ним средства индивидуализации (интеллектуальная собственность), нематериальные блага [2].

3D-модель - это благо, которое может быть объектом гражданских правоотношений. Такого рода модели могут участвовать в гражданском обороте и находиться под защитой от незаконного использования. Все эти особенности характеризуют $3 \mathrm{D}$-модель как объект гражданского права.

В процессе использования 3D-печати могут создаваться как объекты, дизайн которых будет являться новым и оригинальным, 
так и те, которые не будут являться результатом собственного творчества, поскольку в большинстве случаев объект загружается и распечатывается при помощи дизайна, который был создан другим человеком. Получается, что в таких случаях созданный объект будет являться копией существующего коммерческого продукта, а первоначальная модель, разработанная дизайнером, будет охраняться законом как самостоятельное произведение.

Согласно п. 88 Постановления Пленума Верховного суда Российской Федерации от 23 апреля 2019 г. № 10 «О применении части четвертой Гражданского кодекса Российской Федерации»: «Исходя из изложенного исключительное право автора производного или составного произведения возникает в силу факта создания такого произведения, но использоваться такое произведение может только с согласия авторов (других правообладателей) использованных произведений на переработку их произведения или на включение его в составное произведение» [5]. Как отмечает Э.П. Гаврилов: «Следует учитывать, что “создание" произведения является творческим актом, с точки зрения гражданского права это юридический поступок, не волевой акт и не сделка» [1].

Новый объект возникает, когда изменения вносят в его внутреннюю художественную форму, а не просто во внешнюю форму. Изменение только внешней формы, порой не связано с творческой деятельностью, в связи с этим новый объект возникнуть не может.

\section{Правовая охрана 3D-моделей}

Также необходимо определить, под охраной авторского или патентного права должны находиться 3D-модели.

Согласно п. 1 ст. 1255 ГК РФ, «интеллектуальные права на произведения науки, литературы и искусства являются авторскими правами» [3]. Правовая охрана авторского права направлена на каждую творческую работу (но только на ее текст, рисунок и т. п., но не на саму идею) за исключением нормы о признании практической реализации архитектурного, дизайнерского, градостроительного или садово-паркового проекта, закрепленной в подп. 10 п. 2 ст. 1270 ГК РФ. Как отметил В.О. Колятин, для творчества необходим определенный осознанный контроль над процессом, поэтому простое нажатие кнопки обработки изображения (или совершение иных действий над имеющимся материалом) не может сделать лицо автором полученного результата [4].

Для того, чтобы 3D-модель находилась под правовой охраной авторского права, необходимо, чтобы она выражала творческий характер, который будет присущ охраняемому элементу нематериального объекта.

Если мы возьмем оригинальную 3D-модель, которая разработана в графическом редакторе и создана при помощи фантазии дизайнера, то она будет охраняться авторским правом, в качестве произведения графики или дизайна. Права на данную модель будут принадлежать ее автору.

Для авторского права характерен высокий срок охраны. Если 3D-модели взять под охрану авторского права, то мы предполагаем, что из-за большого срока охраны будет затормаживаться развитие экономической, научной, технической деятельности, так как будет невозможно получить из Интернета информацию о неохраняемых технических решениях, необходимых для их реализации.

К патентному праву согласно п. 1 ст. 1345 ГК РФ относятся «интеллектуальные права на изобретения, полезные модели и промышленные образцы» [3].

На первый взгляд можно предположить, что модель, созданная при помощи 3D-печати, не относится к техническим решениям, которые находятся под охраной патентного права. Но, в свою очередь, введение товаров с воплощенными в них изобретениями, моделями и т. д., созданными при помощи 3D-печати, в гражданском обороте будет нарушать исключительное право на патент. Если под 3Dмоделью рассматривать само изделие, полученное при помощи 3D-печати, то его можно считать промышленным образцом, являющимся объектом патентного права.

Получается, что 3D-модели можно зарегистрировать в качестве промышленного образца или в качестве объемных товарных знаков, что в свою очередь позволит получить самостоятельную охрану в этом качестве. 
Как решается вопрос с 3D-моделями, которые содержат в себе запатентованные решения? Этот вопрос неоднозначен. Так, с одной стороны, гл. 72 ГК РФ закрепляет способы использования запатентованных решений, которые реализуются в продукте или изделии, но 3D-модель таковым не является.

Можно сказать, что авторское право направлено на охрану формы нематериального объекта, тогда как патентное право направлено на охрану содержания безотносительно к форме.

На наш взгляд, необходимо учитывать, какой именно объект будет отображен в трехмерной модели, так как от этого будет зависеть, какое право на объекты будет затрагиваться.

\section{Выводы}

Проблема с урегулированием правовой охраны 3D-моделей имеется не только в законодательстве Российской Федерации, но и в других зарубежных странах. В ГК РФ нет нормы, которая урегулировала бы данный вопрос.

В связи с вышеизложенным мы предлагаем сделать следующее: разграничение правовой охраны творческих и нетворческих 3Dмоделей по аналогии баз данных. Творческие базы данных - базы данных, которые могут находиться под охраной авторского права; нетворческие базы данных - под охраной смежного права. Поэтому мы предлагаем внести изменения в ст. 1259,1352 ГК РФ. Необходимо в п. 1 ст. 1259 ГК РФ добавить к существующему перечню объектов авторских прав 3D-модели. Добавить в п. 1 ст. 1352 ГК РФ 5 абзац в следующей редакции: «К промышленному образцу относятся 3D-модели, созданные с использованием аддитивных технологий».

\section{СПИСОК ЛИТЕРАТУРЫ}

1. Гаврилов, Э. «Формат» аудиовизуального произведения и некоторые вопросы права интеллектуальной собственности / Э. Гаврилов // Хозяйство и право. - 2016. - № 3. - С. 64-79.

2. Гражданский кодекс Российской Федерации (часть первая) от 30.11.1994 № 51-Ф3 (после- дняя редакция) // Доступ из справ.-правовой системы «КонсультантПлюс».

3. Гражданский кодекс Российской Федерации (часть четвертая) от 18.12.2006 № 230-Ф3 (последняя редакция) // Доступ из справ.-правовой системы «КонсультантПлюс».

4. Калятин, В. О. Объекты авторского права, созданные с использованием компьютера / В. О. Калятин // Патенты и лицензии. - 2011. - № 5.

5. Постановление Пленума Верховного Суда РФ от 23.04.2019 № 10 «О применении части четвертой Гражданского кодекса Российской Федерации» // Доступ из справ.-правовой системы «КонсультантПлюс».

6. 3D-принтер напечатал роговицу глаза // Новости науки и техники. - Электрон. текстовые дан. - Режим доступа: https://indicator.ru/medicine/ 3d-printer-napechatal-rogovicu-glaza-30-052019.htm. - Загл. с экрана.

7. Lipson, H. Fabricated: The New World of 3D Printing / H. Lipson, M. Kurman. - Wiley, 2013. - 320 p.

8. Disruptive Technologies: Advances That Will Transform Life, Business, and the Global Economy / J. Manyika [et al.]. - Electronic text data. - Mode of access: https://www.mckinsey.com/businessfunctions/digital-mckinsey/our-insights/disruptivetechnologies. - Title from screen.

\section{REFERENCES}

1. Gavrilov E. «Format» audiovizual'nogo proizvedeniya i nekotorye voprosy prava intellektual'noj sobstvennosti ["Format" of an Audiovisual Work and Some Issues of Intellectual Property Law]. Hozyajstvo $i$ pravo, 2016, no. 3, pp. 64-79.

2. Grazhdanskii kodeks Rossiiskoi Federatsii (chast pervaia) ot 30.11.1994 g. № 51-FZ (posledniaia redaktsiia) [Civil Code of the Russian Federation (Part One) of 30.11.1994 No. 51-FZ (Last Edition)]. Access from Reference Legal System "KonsultantPlyus".

3. Grazhdanskii kodeks Rossiiskoi Federatsii (chast chetvertaia) ot 18.12.2006 g. № 230-FZ (posledniaia redaktsiia) [Civil Code of the Russian Federation (Part Four) of 18.12.2006 No. 230-FZ (Last Edition)]. Access from Reference Legal System "KonsultantPlyus".

4. Kalyatin V.O. Ob'ekty avtorskogo prava, sozdannye s ispol'zovaniem komp'yutera [The Objects of Copyright Created Using the Computer]. Patenty i litsenzii [Patents and Licenses], 2011, no. 5.

5. Postanovlenie Plenuma Verkhovnogo Suda RF ot 23.04.2019 № 10 «O primenenii chasti chetvertoi Grazhdanskogo kodeksa Rossiiskoi Federatsii» [Resolution of the Plenum of the Supreme Court of the 


\section{ВОПРОСЫ ЧАСТНОПРАВОВОГО РЕГУЛИРОВАНИЯ}

Russian Federation dated April 23, 2019 No. 10 “On the Application of Part Four of the Civil Code of the Russian Federation"]. Access from Reference Legal System "KonsultantPlyus".

6. Novosti nauki i tekhniki [News of Science and Technology]. URL: https://indicator.ru/medicine/ 3d-printer-napechatal-rogovicu-glaza-30-052019.htm.
7. Lipson H., Kurman M. Fabricated: The New World of 3D Printing. Wiley, 2013. $320 \mathrm{p}$.

8. Manyika J., Chui M., Bughin J., Dobbs R., Bisson P., Marrs A. Disruptive Technologies: Advances That Will Transform Life, Business, and the Global Economy. URL: https://www.mckinsey.com/ business-functions/digital-mckinsey/our-insights/ disruptive-technologies.

\section{Information About the Author}

Victoria A. Ammalainen, Lecturer, Department of Civil Law Disciplines, Volgograd Academy of the Ministry of Internal Affairs of the Russian Federation, Istoricheskaya St, 130, 400089 Volgograd, Russian Federation, Ammalaynen@yandex.ru, https://orcid.org/0000-0003-3542-1334

\section{Информация об авторе}

Виктория Алексеевна Аммалайнен, преподаватель кафедры гражданско-правовых дисциплин, Волгоградская академия Министерства внутренних дел Российской Федерации, ул. Историческая, 130, 400089 г. Волгоград, Российская Федерация, Ammalaynen@yandex.ru, https://orcid.org/0000-0003-3542-1334 